\title{
XL. Report of cases in the Finsbury Dispensary, from the 1st of January to the 31st of March 1806
}

\author{
John Taunton Esq.
}

To cite this article: John Taunton Esq. (1806) XL. Report of cases in the Finsbury Dispensary, from the 1st of January to the 31st of March 1806, Philosophical Magazine Series 1, 24:95, 221-222, DOI: $10.1080 / 14786440608563369$

To link to this article: http://dx.doi.org/10.1080/14786440608563369

曲 Published online: 18 May 2009.

Submit your article to this journal $\sqsubset \pi$

Џ Article views: 2

Q View related articles $\asymp$ 


\section{$\left[\begin{array}{lll}{[291} & 3\end{array}\right.$}

XI. Report of Cases in the Finslury Dispensary, from the 1 st of January to the 31 st of March 1806. By John Taunton, Esq. Surgeon to the City and Finslury Dispensaries, and Lecturer on Anatomy, Physiology, and Surgery.

Since last report (Phil. Mag. vol. xxiii. p. 312.) there have been admitted into this dispensary 160 patients.

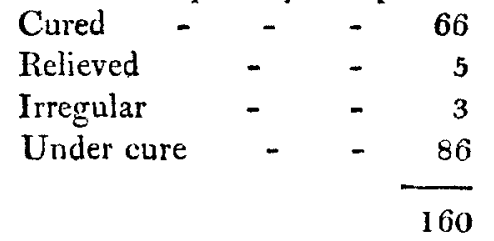

Of these, 33 have been visited at home, and eight have submitted to operations.

In the last surgical report (see January) there were $\mathbf{8 0}$ patients under cure, 70 of whom have been cured and 10 relieved, 18 have been home patients, and two have undergone operations.

Mrs. Cuffee, æt. 50, has been subject to rheumatism and asthma for several years. She observed a tumour in her left brcast some years ago, irregular on its surface and occasionally attended with darting pain, which was not severe, so as to excite much attention, till March 1805, when the breast had increased much in size, and was become very painful. The unfavourable symptoms coutinuing, she was admitted into the dispensary in November last; but, owing to her bad state of health, nothing could be done at that time to remove the disease in her breast. In January, her health being improved, it was determined, in consultation, to propose the operation, that being the only mode of treatment likely to give her any chance for recovery. To this she readily consented, and requested that an early day might be named for its performance.

The operation was performed on the 28th of January, which she underwent with the greatest fortitude, and had very little symptomatic fever considering its magnitude: as she had naturally a very full breast, the size of which was much increased by the disease, the wound filled with granu- 
lations, and was completely cicatrized in much less time than could have been expected from its size, as the incision was 14 inches in length, and a large portion of the integuments were necessarily removed.

Mrs. F., xt. 31, has had several children, and always enjoyed good health previous to the present disease. About the end of May she observed a tumour on the lower part of the neck, but, as it was not attended with much pain, it did not excite much attention: from the beginning it appeared to be very hard and immovable, and, as it increased in size, it impered respiration and deglutition.

She was admitted into the dispensary on the 21st of September, when the tumour was become very painful both in deglutition and respiration, and, from its rapid enlargement, had much alarmed the patient. It was found to be an exostosis of the clavicle, near its connection with the sternum. It reached to the upper part of the larynx, and its base where it grew from the clavicle was more than three inches in length, and it must have been more than nine inches in circumference. In this case little was to be expected from any mode of treatment short of an operation; which must have been attended with great danger, as the tumour grew from the inner as well as from the upper surface of the clavicle, and was nearly in contact with the carotid artery.

Cicuta fomentations were ordered with a view to alleviate the pain ; in which they happily succeeded, and appearcd to arrest the growth of the tumour. She took the infusion of quassia, and the fomentations were continued till the 17 th of October, when it was evident that the tumour had not increased, and the pain was much lessened during the above period. The emp. hydrarg. cum ammoniac. was applied, with a view to increase the action of the absorbents : some magnesia vitriolata was taken occasionally, and the plaster renewed once in about every ten or twelve days: the tumour gradually decreased in size, was entirely discussed by the end of December, and she was discharged cured on the 6 th of January 1806.

Greville-street, Hatton-garden, April 5, 180).

XLI. On 